\title{
Recruitment of Multiple Pathways to Ventral Tegmental Area during Cocaine-Seeking Behavior
}

\author{
Sindy Cole, ${ }^{1}$ Teri M. Furlong, ${ }^{2}$ and Christina J. Perry ${ }^{3}$ \\ ${ }^{1}$ Department of Psychology, Boston College, Chestnut Hill, Massachusetts 02467, ${ }^{2}$ Brain and Mind Research Institute, University of Sydney, Sydney, New \\ South Wales 2050, Australia, and ${ }^{3}$ Florey Neuroscience Institutes, University of Melbourne, Melbourne, Victoria 3010, Australia \\ Review of Mahler and Aston-Jones
}

The mesocorticolimbic dopamine system is a major neural substrate underlying appetitive behaviors, including drugseeking. Because the midbrain ventral tegmental area (VTA) is one of two major sources of dopamine to cortical and subcortical areas, it has been the focus of much experimental inquiry into the mechanisms underlying drug-seeking behavior. Such research has demonstrated that the VTA is particularly important for motivated behavior guided by rewardassociated cues. Drug-associated environments and other drug-paired stimuli have the ability to reinstate previously extinguished drug-seeking behavior, and neurotransmission in VTA critically contributes to such context- and cue-induced relapse (Feltenstein and See, 2008). Most research aimed at delineating the neural circuitry underlying reinstatement has focused on how the VTA and its projection areas, especially the nucleus accumbens (NAc) and medial prefrontal cortex (mPFC) promote reward-seeking behavior. Significantly less well understood, however, is how VTA responses to such reward-associated cues are shaped by VTA afferents. This important topic was

\footnotetext{
Received Nov. 17, 2012; revised Dec. 15, 2012; accepted Dec. 18, 2012. We thank Professor Andrew Lawrence and Dr. Gorica Petrovich for their helpful comments on the manuscript.

Correspondence should be addressed to Sindy Cole, Department of Psychology, Boston College, 140 Commonwealth Avenue, Chestnut Hill, MA 02467. E-mail: sindy.cole@bc.edu.

DOI:10.1523/JNEUROSCI.5338-12.2013

Copyright $\odot 2013$ the authors $\quad 0270-6474 / 13 / 332239-03 \$ 15.00 / 0$
}

explored in a recent article in The Journal of Neuroscience.

Mahler and Aston-Jones (2012) used neural tract-tracing in conjunction with detection of Fos induction to identify structures that provide input to VTA and are active during reinstatement of cocaineseeking. The retrograde neural tracer cholera toxin $\mathrm{B}(\mathrm{CTb})$ was deposited into VTA to label neurons that project into VTA, and rats were then trained to press a lever to receive an intravenous cocaine infusion. The infusion was paired simultaneously with an audiovisual cue. After the response was acquired, animals underwent extinction, where lever-pressing resulted in neither cocaine delivery nor cue presentation, and resulted in reduced responding on the lever. In a subsequent session, when lever presses resulted in presentation of the cocaine-associated cue (but not cocaine), animals showed reinstatement of lever-pressing behavior. This retrieval of extinguished responding is defined as cue-induced reinstatement of cocaine-seeking. Rats presented with a distinct audiovisual cue that was never paired with cocaine did not show this reinstatement.

In a comprehensive analysis, Mahler and Aston-Jones (2012) identified several forebrain regions that projected to the VTA and showed increased activity during cue-induced reinstatement. These regions included the ventral pallidum (VP), NAc shell, NAc core, and the lateral hypothalamus (LH). Additionally the authors identified two sets of VTA afferents, from the lateral habenula ( $\mathrm{LHb}$ ) and tail of the VTA (tVTA), that showed greater activity during extinction, when drug-seeking was inhibited, than during reinstatement.

The findings of Mahler and Aston-Jones (2012) contribute to a growing literature that suggests divergent neural circuits mediate cue-induced versus context-induced reinstatement of drug-seeking behaviors. For example, in an earlier study, Hamlin et al. (2008) also used retrograde tract-tracing combined with Fos immunohistochemistry to examine the neural bases (including VTA afferents) of context-induced reinstatement of cocaine-seeking. Although there were some similarities in the results of these two studies, such as a lack of activation in VTAprojecting $\mathrm{mPFC}$ neurons during reinstatement, there was also at least one important difference. Hamlin and colleagues demonstrated that the LH was selectively recruited during context-induced reinstatement (indexed by Fos-positive single-labeled neurons), but this contribution did not involve direct LH projections to VTA (no difference in CTb-Fos double-labeled neurons). In contrast, Mahler and Aston-Jones (2012) showed that a direct LH-VTA pathway was selectively recruited during cue-induced reinstatement.

There are two key differences between these studies regarding the circumstances under which responding was retrieved. In the Mahler and Aston-Jones (2012) study, not only was the reinstating cue a discrete audiovisual cue, but its presence was also 
contingent on lever-pressing by the animal so that the animals were not exposed to the cue until the first response was performed. In contrast, in the Hamlin et al. (2008) study, the reinstating cue was the context where cocaine was previously available (distinct from the extinction context). As such, its presence was not dependent on the behavior of the animal, and preceded the first response. It is possible then, that reinstatement precipitated by a discrete cue presented before leverpress may result in a pattern of neural activation more similar to that described by Hamlin et al. (2008). Regardless, the subtle difference observed in the results of these studies has much broader implications, suggesting that even though there may be some overlap in the neural circuits underlying different reinstatement paradigms, such common neural sites (e.g., LH) exert their regulatory effects through distinct connections.

The hypothalamic neuropeptide orexin (hypocretin) has been implicated in cueinduced reinstatement of cocaine-seeking (Smith et al., 2009). Therefore, Mahler and Aston-Jones (2012) sought to determine whether orexin neurons formed part of the LH-VTA projection recruited during cued reinstatement. While a number of orexin neurons colabeled with CTb expressed Fos, they were unable to detect a reinstatementspecific induction of Fos in these neurons, and therefore were unable to confirm a role for orexin-VTA afferents in reinstatement. Nevertheless, the observed recruitment of a non-orexin population of neurons provides an interesting avenue for further inquiry. The authors suggest that the activated neurons might be those that produce melaninconcentrating hormone $(\mathrm{MCH}) . \mathrm{MCH}$ is another neuropeptide that, like orexin, is synthesized exclusively in the dorsal hypothalamus and has been implicated in cueinduced reinstatement of cocaine-seeking (Chung et al., 2009). However, such neurons are unlikely to be the source of the recruited LH-VTA afferents seen by the authors, because unlike orexin neurons, which readily express Fos (Mahler and Aston-Jones, 2012, their Fig. 9), the capacity of $\mathrm{MCH}$ neurons to produce Fos is extremely limited (Bahjaoui-Bouhaddi et al., 1994). Therefore, using a different technique, such as intra-VTA infusion of an $\mathrm{MCH}$ receptor antagonist during reinstatement, would be necessary to identify any functional connections between $\mathrm{MCH}$ neurons and VTA during reinstatement.

It seems, then, that the active LH-VTA afferents are likely a different population of neurons that do not express orexin or
$\mathrm{MCH}$. One likely candidate is those neurons that colocalize neurotensin (NT) and corticotropin-releasing factor (CRF) and use Fos as a transcription factor (Elias et al., 2000). Importantly, central infusion of either NT or CRF reinstates cocaineseeking (Lopak and Erb, 2005; Erb et al., 2006). It is worth noting, however, that there are multiple extrahypothalamic sources of NT and CRF input to VTA. Therefore, labeling NT/CRF neurons, in combination with retrograde labeling and Fos, would not only be a first step in establishing a role for hypothalamic NT and/or CRF in reinstatement, but might also identify the non-orexin LH neurons driving VTA.

It is also worth considering how structures that were previously found to be involved in cue-induced reinstatement, but that were not identified in the experiment by Mahler and Aston-Jones (2012), may influence VTA through the areas that were found to be activated. For example, prior research has demonstrated that both the amygdala and the mPFC are critically involved in reinstatement (Feltenstein and See, 2008), and although VTA afferents from neither region expressed reinstatement-specific Fos activity in the study by Mahler and Aston-Jones (2012), both structures have been shown to influence the NAc during reward-seeking behaviors (Ambroggi et al., 2008; Stuber et al., 2011; Bossert et al., 2012). Therefore, information from the amygdala and $\mathrm{mPFC}$ might influence VTA via the NAc. Interestingly, the VP also receives substantial input from the amygdala and $\mathrm{mPFC}$, as well as dense projections from NAc (Grove, 1988; Groenewegen et al., 1999). Thus, it may be that reinstatement of cocaine-seeking is driven, at least in part, through these cortico-striatopallidal-tegmental projections. Which of these activated inputs critically elicit the VTA activity that promotes reinstatement, as well as how this proposed circuit relates to cue-induced reinstatement specifically, requires further examination.

Finally, as well as identifying VTA afferents recruited during reinstatement, Mahler and Aston-Jones (2012) reported that input from both LHb and tVTA was activated by extinction conditions. This finding, combined with prior research demonstrating that LHb and tVTA are associated with aversion-associated behaviors, led the authors to suggest a possible role for these structures in the suppression of cocaine-seeking. Of particular relevance to this suggestion are the findings of a recent study that used optogenetics in conjunction with viral-mediated tracing methods and ex vivo electrophysiology to examine the function and connectivity of LHb inputs to VTA (Lammel et al., 2012). Lammel and colleagues found that selectively stimulating VTA-projecting LHb neurons was sufficient to induce conditioned place aversion. Furthermore, this stimulation both activated a subpopulation of VTA dopamine neurons that project to $\mathrm{mPFC}$, and inhibited VTA projections to NAc (most likely through feedforward inhibition from activation of GABAergic cells in tVTA). Together, these findings suggest that LHb control over VTA both directly, and indirectly through tVTA, could be involved in the inhibition of cocaine-seeking behavior. Such a role may be exerted through excitation of a LHb-VTA-mPFC pathway, with simultaneous inhibition of VTA-NAc projections. Further studies are needed to confirm this possible role for LHb/tVTA in the suppression of cocaine-seeking behavior.

In summary, Mahler and Aston-Jones (2012) have provided important insight into brain structures that potentially mediate VTA activity during cue-induced reinstatement. Perhaps of most interest is the finding that distinct subpopulations of neurons within the VTA, which belong to divergent circuits, may exert bidirectional control over responding. Specifically, activity of VTA afferents from striatal and hypothalamic regions may promote reinstatement of cocaine-seeking, while input from LHb and tVTA may modulate VTA activity resulting in the inhibition of such drug-seeking behavior. Overall these results suggest multiple avenues for future research. First, it is important to extend and compare the current findings to those seen for other reward-driven behaviors. Differences were evident in the VTA afferents recruited during cue-induced reinstatement here, and context-induced reinstatement previously (Hamlin et al., 2008). Such differences may extend to other relapse models, as well as for alternate drug classes (Badiani et al., 2011). Second, further investigation into characterizing the active hypothalamic inputs to VTA will provide a useful addition to the literature regarding the role of hypothalamic peptides in drug-seeking behaviors. Finally, confirming a role for LHb/tVTA in the extinction of cocaine-seeking offers the potential for significant advancement in the understanding of how the VTA guides such motivated behavior.

\section{References}

Ambroggi F, Ishikawa A, Fields HL, Nicola SM (2008) Basolateral amygdala neurons facilitate 
reward-seeking behavior by exciting nucleus accumbens neurons. Neuron 59:648-661. CrossRef Medline

Badiani A, Belin D, Epstein D, Calu D, Shaham Y (2011) Opiate versus psychostimulant addiction: the differences do matter. Nat Rev Neurosci 12:685-700. CrossRef Medline

Bahjaoui-Bouhaddi M, Fellmann D, Griffond B, Bugnon C (1994) Insulin treatment stimulates the rat melanin-concentrating hormoneproducing neurons. Neuropeptides 27:251-258. CrossRef Medline

Bossert JM, Stern AL, Theberge FR, Marchant NJ, Wang HL, Morales M, Shaham Y (2012) Role of projections from ventral medial prefrontal cortex to nucleus accumbens shell in context-induced reinstatement of heroin seeking. J Neurosci 32:4982-9491. CrossRef Medline

Chung S, Hopf FW, Nagasaki H, Li CY, Belluzzi JD, Bonci A, Civelli O (2009) Melaninconcentrating hormone system modulates cocaine reward. Proc Natl Acad Sci U S A 106: 6772-6777. CrossRef Medline

Elias CF, Kelly JF, Lee CE, Ahima RS, Drucker DJ,
Saper CB, Elmquist JK (2000) Chemical characterization of leptin-activated neurons in the rat brain. J Comp Neurol 423:261-281. CrossRef Medline

Erb S, Petrovic A, Yi D, Kayyali H (2006) Central injections of CRF reinstate cocaine seeking in rats after postinjection delays of up to $3 \mathrm{~h}$ : an influence of time and environmental context. Psychopharmacology 187:112-120. CrossRef Medline

Feltenstein MW, See RE (2008) The neurocircuitry of addiction: an overview. Br J Pharmacol 154:261-274. Medline

Groenewegen HJ, Wright CI, Beijer AV, Voorn P (1999) Convergence and segregation of ventral striatal inputs and outputs. Ann N Y Acad Sci 877:49-63. CrossRef Medline

Grove EA (1988) Neural associations of the substantia innominata in the rat: afferent connections. J Comp Neurol 277:315-346. CrossRef Medline

Hamlin AS, Clemens KJ, McNally GP (2008) Renewal of extinguished cocaine-seeking. Neuroscience 151:659-670. Medline

Lammel S, Lim BK, Ran C, Huang KW, Betley MJ,
Tye KM, Deisseroth K, Malenka RC (2012) Input-specific control of reward and aversion in the ventral tegmental area. Nature 491:212-217. CrossRef Medline

Lopak V, Erb S (2005) Activation of central neurotensin receptors reinstates cocaine seeking in the rat: modulation by a D1/D5, but not D2/D3, receptor antagonist. Psychopharmacology 182:297-304. CrossRef Medline

Mahler SV, Aston-Jones GS (2012) Fos activation of selective afferents to ventral tegmental area during cue-induced reinstatement of cocaine seeking in rats. J Neurosci 32:13309-13325. CrossRef Medline

Smith RJ, See RE, Aston-Jones G (2009) Orexin/ hypocretin signaling at the orexin 1 receptor regulates cue-elicited cocaine-seeking. Eur J Neurosci 30:493-503. CrossRef Medline

Stuber GD, Sparta DR, Stamatakis AM, van Leeuwen WA, Hardjoprajitno JE, Cho S, Tye KM, Kempadoo KA, Zhang F, Deisseroth K, Bonci A (2011) Excitatory transmission from the amygdala to nucleus accumbens facilitates reward seeking. Nature 475:377-380. CrossRef Medline 